\title{
Comparison of visual aids for improving reading performance in children with dyslexia
}

\author{
Rokiah Omar ${ }^{1}$, Noor Halilah Buari ${ }^{2}$, Chiranjib Majumder ${ }^{1}$ and Victor Feizal Knight ${ }^{3}$ \\ ${ }^{1}$ Optometry and Vision Science Program, Centre for Community Health Studies (ReaCH), Faculty of Health Sciences, Universiti \\ Kebangsaan Malaysia \\ ${ }^{2}$ Centre of Optometry, Faculty of Health Sciences, Universiti Teknologi MARA Cawangan Selangor, Puncak Alam Campus, \\ Bandar Puncak Alam, Selangor Darul Ehsan, Malaysia \\ ${ }^{3}$ Faculty of Medicine and Defence Health, National Defence University of Malaysia, Sungai Besi Campus, Kuala Lumpur, Malaysia
}

\begin{abstract}
Background: Dyslexia is a key learning disorder associated with reading difficulties in children. The purpose of this study was to determine the effectiveness of simple visual devices in improving the reading performance of children with dyslexia.

Methods: A case-control study was conducted by selecting 80 school children with dyslexia, aged 8-11 years, from the Special Dyslexic School Program of the Ministry of Education (MOE) Malaysia. Subjects were randomly assigned to four groups: the typoscope, magnifier, visual tracking magnifier (VTM), and control groups. Reading performance was measured based on reading speed and reading error rate. The time taken to complete reading of text was measured, and reading errors were recorded. The reading performance of each group was assessed at baseline, week 2, week 6, and week 12 .

Results: Reading performance was significantly different $(P<0.05)$ for both Level 1 and Level 2, before and after intervention only in children with dyslexia using magnifiers and VTM. Reading performance for children with dyslexia using a magnifier or a VTM increased significantly $(P<0.05)$ from baseline to week 2 , week 6 , and week 12 . The improvement in reading speed was 2.5 times faster for children in the VTM group than in the other groups.

Conclusions: Simple visual aids, such as a VTM and magnifying glass, improved reading performance in children with dyslexia. The VTM intervention yielded the greatest improvement after 12 weeks of intervention. Hence, it is suggested that a VTM be used as part of a rehabilitation program for all children with dyslexia in Malaysia, particularly those in dyslexia programs in schools under the MOE Malaysia. However, future studies with longer follow-up periods are needed to confirm the sustainability of this improved reading performance after discontinuation of the intervention.
\end{abstract}

\section{KEYWORDS}

dyslexia, children, visual tracking magnifier, typoscope, simple magnifier, reading performance, reading speed, reading rate, reading error rate

\section{INTRODUCTION}

Dyslexia is a major learning disorder associated with reading difficulties among children. Worldwide prevalence estimates for dyslexia range from 4 to $10 \%$ [1-6]. In Malaysia, almost 7\% of third-grade students and nearly $4 \%$

Correspondence: Rokiah Omar, Professor, Optometry and Vision Science Program, Centre for community health studies (ReaCH), Faculty of Health Sciences, Universiti Kebangsaan Malaysia. Jalan Raja Muda Abdul Aziz, 50300 Kuala Lumpur, Malaysia. Email: r_omar@ukm.edu.my. ORCID iD: https://orcid. org/0000-0001-9485-1620

How to cite this article: Omar R, Buari NH, Majumder C, Knight VF. Comparison of visual aids for improving reading performance in children with dyslexia. Med Hypothesis Discov Innov Optom. 2021 Summer; 2(2): 85-93. https://doi.org/10.51329/mehdioptometry130

Received: 23 July 2021; Accepted: 10 November 2021

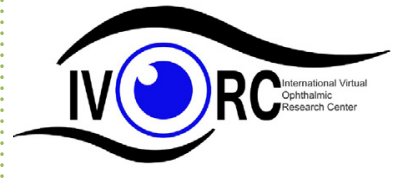

Copyright (C) Author(s). This is an open-access article distributed under the terms of the Creative Commons Attribution-NonCommercial 4.0 International License (http://creativecommons.org/licenses/by-nc/4.0/) which permits copy and redistribute the material just in noncommercial usages, provided the original work is properly cited. (c) (i) (8) 
of university graduates in Malaysia are at risk of developing dyslexia [7]. Without good reading capabilities, comprehension may be affected; hence, children with dyslexia will have a disadvantage when compared to their school peers. Consequently, improving reading performance among children with dyslexia is crucial to ensure that they can participate equally in learning opportunities.

Various interventions have been introduced to help children with dyslexia. Among them are the use of tinted lenses or colored overlays to address reading difficulties and symptoms of asthenopia, to improve reading performance $[8,9]$. Sharanjeet et al. have shown that the use of print on blue paper can increase the reading speed of children with dyslexia as compared to print on white paper [10]. Exercise therapy, such as monocular occlusion using glasses with yellow lenses, and short-term occlusion of the left eye can also overcome the problem of binocular instability, so that children with dyslexia achieve binocular fixation permanently and have significantly improved reading performance [11].

Several tools have been suggested for children with dyslexia, including typoscopes, Dex frames, and the COIL visual tracking magnifier (VTM) [12]. However, the use of the Dex frames tool showed no significant improvement in reading performance, in terms of speed or reading accuracy, in a previous study [13]. More recent studies have shown that children with dyslexia demonstrated improvement in reading performance when the crowding effect was reduced or letter spacing was improved $[14,15]$. Moreover, a study by Bucci et al. showed that computer-based oculomotor training improved reading proficiency by reducing the time of reading and fixation duration in children with dyslexia [16]. Similarly, another study showed that rhythmic reading training improved reading speed and accuracy, as compared to Bakker's visual hemisphere-specific stimulation and action video game training, methods that had already been validated [17].

However, all of the above interventions are quite complicated and require children to be present at a clinic. Hence, it is important to determine if any other simple tools can benefit children with dyslexia to improve their reading performance without requiring their presence at a clinic. Therefore, this study aimed to examine the effectiveness of using several simple vision aids, such as a typoscope, magnifying glasses, and a VTM, on improving reading performance among children with dyslexia. If these methods prove effective, it would provide a new intervention protocol for children with dyslexia that can be conducted during school to address their reading difficulties. This would allow children with dyslexia to focus on learning, without the barrier of a reading disability. In addition, without reading difficulties, children with dyslexia are likely to be more interested in engaging in reading activities.

\section{METHODS}

This was a case-control study involving children with dyslexia. This study followed the Helsinki Declaration for Human Subjects and was approved by the Universiti Kebangsaan Malaysia (UKM) Research and Medical Ethics Research Committee. This study was also approved by the Ministry of Education (MOE), and informed consent was obtained from the participants' parents.

Children with dyslexia were randomly selected from 11 schools in Selangor, Wilayah Persekutuan, Negeri Sembilan, Melaka, and Perak, from the Special Dyslexic School Program of the MOE Malaysia. The sample size $(\mathrm{n})$ required for this study was calculated based on Seki et al.: $\mathrm{n}=\left(\mathrm{Z}^{*} \sigma / \Delta\right)^{2}$, where $\mathrm{Z}$ is 1.96 for the $95 \%$ confidence interval, and $\sigma$ is the standard deviation of reading speed $(6.728 \mathrm{~s})$ found by Seki et al. for children with dyslexia [18], and $\Delta$ is the mean difference in reading speed between children with and without dyslexia $(2.88 \mathrm{~s})$. Therefore, the minimum sample size required was computed as 20 children with dyslexia in each group. Participants were randomly assigned to four groups: a) typoscope group, b) simple magnifier group, c) VTM group, and d) control group. The control group participants followed the standard dyslexic intervention program provided by the MOE Malaysia in their respective schools and were not provided with any reading aids in this study $[19,20]$.

A typoscope (COIL, Desa Pandan, KL, Malaysia) (Figure 1A) is a rectangular, non-optical vision aid with a size of $9 \times 12.5 \mathrm{~cm}$ and a $1.3-\mathrm{cm}$ aperture at the top that provides good contrast and improves reading focus, as shown in Figure 1A. The second visual aid was a simple magnifier (COIL, Desa Pandan, KL, Malaysia) with a magnification of $1.7 \times, 18.9$ diopters (D), and $143 \times 104 \mathrm{~mm}$ field-of-view that can be placed above the reading text, as shown in Figure 1B. Lastly, the VTM, a magnifying lens of $1.7 \times$ magnification and a 7-mm reading aperture at the center of the lens, is shown in Figure 1C. The VTM used in this study has a gray filter at the top and bottom of a semi-circular reading opening to reduce distortion and glare while also improving the reading text contrast. There is also a dark line that allows the user to maintain a readable line of text. The lens is $18.9 \mathrm{D}$ with a $143 \times 104$-mm-wide viewing area and has a soft rubber grip around the lens.

The MOE Malaysia defines Level 1 as primary school children aged 7-9 years, and Level 2 as primary school 
children aged 10-12 years $[21,22]$. The children were divided into Level 1 and Level 2 based on the level word difficulties that they could comprehend. Each group consisted of children aged between 8 and 11 years, from Year 2 to Year 5. Year 1 and Year 6 children with dyslexia were excluded from this study due to restrictions by the MOE, as Year 6 would be attending an important examination, while Year 1 children would still be adapting to a new learning environment in school. All participants underwent the same examination and evaluation protocol. The inclusion criteria were students diagnosed with dyslexia, aged between 8 and 11 years, with a normal level of intelligence (IQ) determined by the Raven Colored Progressive Matrices Test, no health problems that could interfere with the ability to read or to hold test instruments, no convergence difficulties, and binocular vision level with correction of 6/9 or better. Those who fulfilled the inclusion criteria for vision examination underwent evaluation of best-corrected distance and near visual acuity (BCDVA and BCNVA, respectively), accommodation and convergence tests, and subjective refraction. Those who required spectacles were provided these, and they were only enrolled in the study after a 1-month adaptation using the new prescription spectacles.

The reading performance test was performed as follows: Reading performance was measured based on reading speed and reading rate. Reading speed is the time taken to read a text, and the unit is words per minute (wpm) [23]. The reading rate is obtained by dividing the number of words correctly read by the duration of the reading time, and the unit is also wpm. The UKM Malay Language-Related Word Reading Text Test consists of 10 different paragraphs with 50 words for Level 1 and Level 2 .

All participants underwent a reading performance test, i.e. reading speed test, using a randomly chosen text, at every review visit. This was done to ensure that the participants did not memorize the reading text test. The time required to complete reading each paragraph was recorded and analyzed. For each level, the reading speed was categorized into three categories: normal, slow, and very slow. If a child read within -2 standard deviations (SDs) of the normal reading range, it was categorized as a slow reading speed. Very slow reading performance was defined as when reading speed was $-3 \mathrm{SD}$ from the normal reading speed range. The range of reading performance for children without dyslexia at Levels 1 and 2, was adopted from the results of our previous study on reading performance among primary school children without dyslexia using the Malay Language Related Reading Text Test [23]. Each participant was supplied with either a typoscope, simple magnifier, or VTM, according to their group assignment, to be used as reading aids during school sessions only, except for the control group, which used only the standard MOE dyslexia intervention. This design was to ensure that each participant had an equal duration of exposure to the visual aids provided. The time taken to complete reading of each text was measured, and any errors were recorded. Subsequently, reading performance tests, i.e. reading speed, was performed at week 0 (baseline), week 2 , week 6 , and week 12 . Results were recorded and analyzed. A flow chart of the study is shown in Figure 2.

The data were analyzed using IBM SPSS Statistics for Windows, version 21.0 (IBM Corp., Armonk, NY, USA). The normality of the data distribution was investigated using the Shapiro-Wilk test. Based on these test results, comparison of reading speed between pre-and post-intervention for control, typoscope, simple magnifier, and VTM for Levels 1 and 2 were performed using the Wilcoxon rank test. Statistical significance was set at $P<0.05$.

\section{RESULTS}

Eighty children with dyslexia participated, and the mean descriptive data for vison tests conducted prior to the intervention assessment are tabulated in Table 1. The children with dyslexia reading performance, based on reading speed of the related text, at baseline, weeks 2, 6, and 12 for Levels 1 and 2 are illustrated in Figure 3

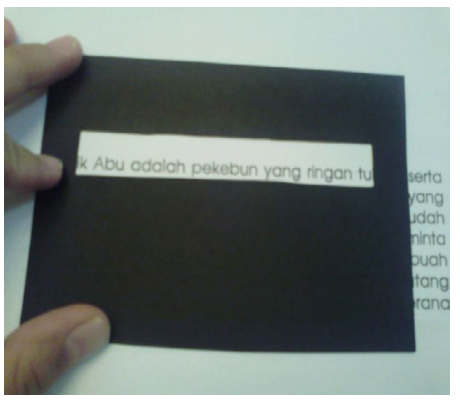

(A) Typoscope

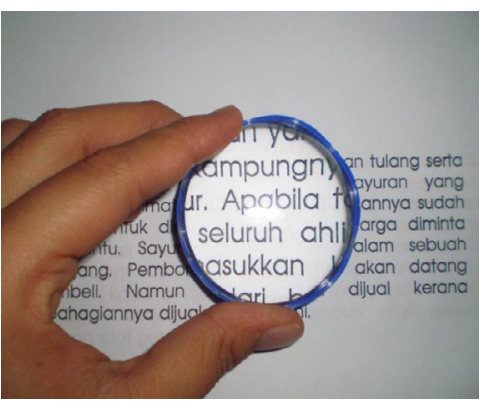

(B) Simple Magnifier

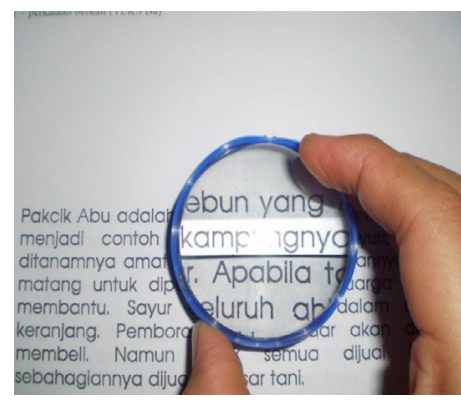

(C) Visual Tracking Magnifier (VTM)

Figure 1. Types of visual aids used for dyslexia intervention in the different study groups. 


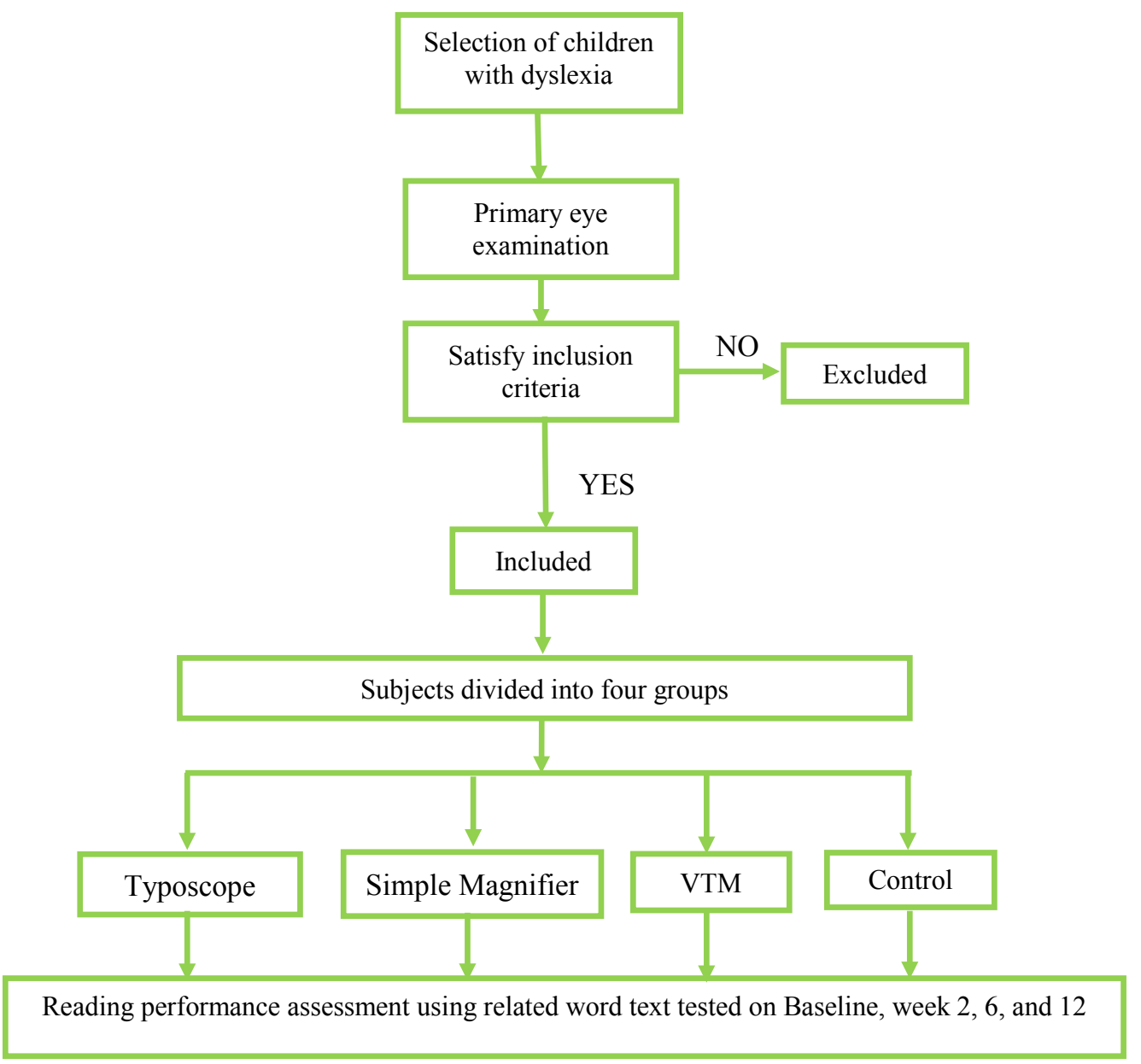

Figure 2. Flow chart for inclusion of children with dyslexia, based on reading performance assessment, according to the type of reading aid supplied in the study. Abbreviation: VTM, visual tracking magnifier.

Table 1. Mean descriptive baseline data for vision tests of 80 children with dyslexia

\begin{tabular}{|l|l|}
\hline Variable & Mean \pm SD (Range) \\
\hline Best-corrected distance VA OD (logMAR) & $0.01 \pm 0.02(0.00$ to 0.05$)$ \\
\hline Best-corrected distance VA OS (logMAR) & $0.01 \pm 0.01(0.00$ to 0.04$)$ \\
\hline Best-corrected distance VA OU (logMAR) & $0.00 \pm 0.00(0.00$ to 0.03$)$ \\
\hline Best-corrected near VA OD (logMAR) & $0.00 \pm 0.01(0.00$ to 0.03$)$ \\
\hline Best-corrected near VA OS (logMAR) & $0.00 \pm 0.02(0.00$ to 0.04$)$ \\
\hline Best-corrected near VA OU (logMAR) & $0.00 \pm 0.01(0.00$ to 0.03$)$ \\
\hline Amplitude of accommodation OD (D) & $14.81 \pm 1.88(10$ to 21.0$)$ \\
\hline Amplitude of accommodation OS (D) & $14.60 \pm 1.89(10$ to 21.5$)$ \\
\hline Amplitude of accommodation OU (D) & $14.74 \pm 1.79(10$ to 21.0$)$ \\
\hline Convergence (cm) & $4.52 \pm 0.94(4$ to 10$)$ \\
\hline Spherical equivalent OD (D) & $-0.03 \pm 0.89$ (+ 0.25 to -0.25$)$ \\
\hline Spherical equivalent OS (D) & $-0.03 \pm 0.98$ (0.00 to 0.25$)$ \\
\hline IQtest (score) & $29.5 \pm 23.3(34.0$ to 22.0$)$ \\
\hline
\end{tabular}

Abbreviations: SD, standard deviation; VA, visual acuity; OD, right eye; OS, left eye; OU, both eyes; logMAR, logarithm of the minimum angle of resolution; $D$, diopter; $\mathrm{cm}$, centimeter; $\mathrm{IQ}$ intelligence quotient. 


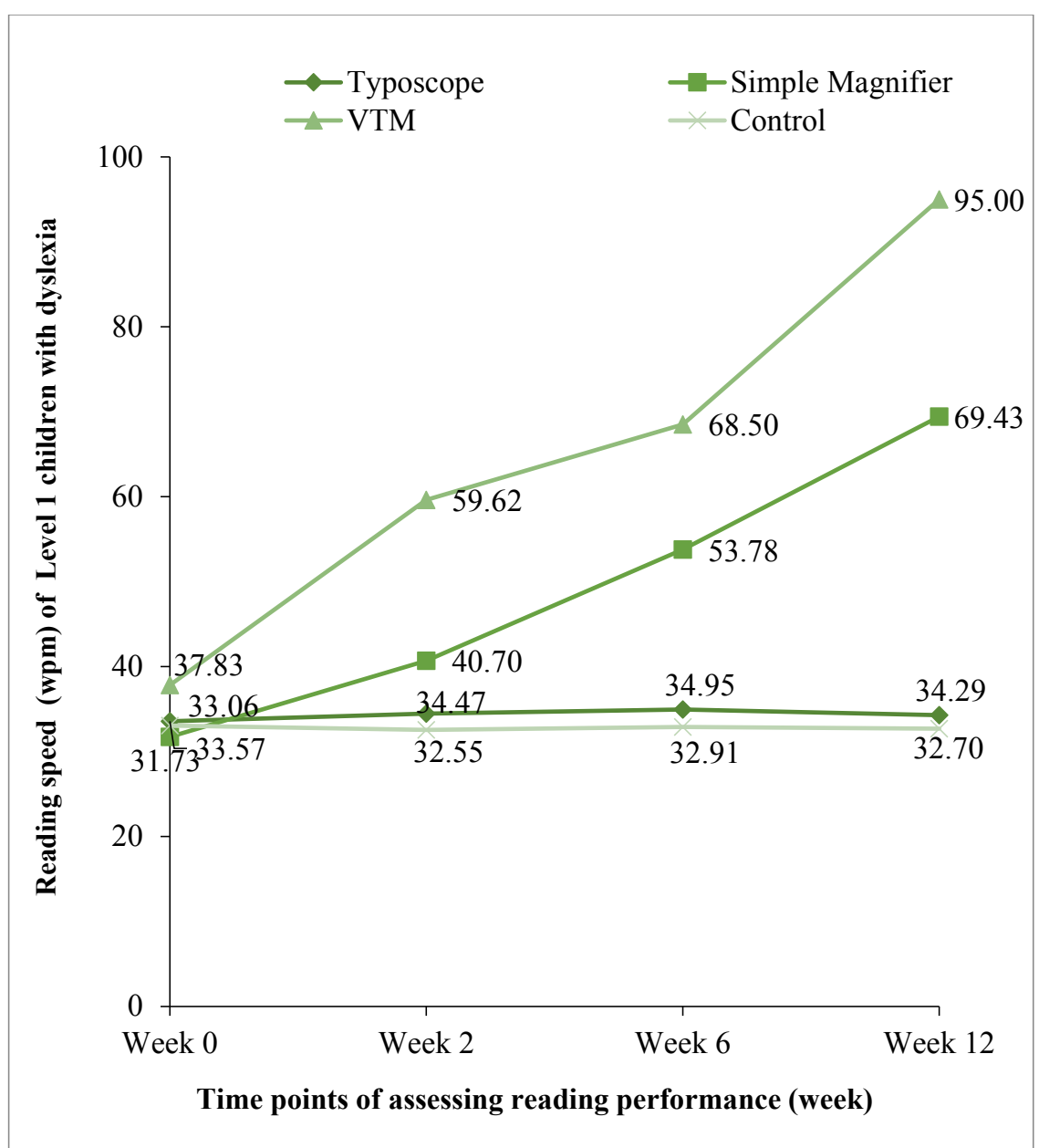

Figure 3. Reading performance of Level 1 children with dyslexia, assessed by reading speed (word per minute [wpm]) using the UKM Malay Language-Related Word Reading Text Test, with different types of visual aids.

and Figure 4 for Level 1 and Level 2, respectively. As Figure 3 shows, Level 1 children with dyslexia who used a VTM showed the best improvement in reading speed, followed by those in the simple magnifier, typoscope, and control groups. A similar trend of improvement was observed for reading performance using the related text for Level 2, as shown in Figure 4. The reading performance, that is, reading speed, of the children with dyslexia in the VTM group at baseline was $35.88 \mathrm{wpm}$. This started to improve at week 2, with a reading speed of $57.04 \mathrm{wpm}$, representing an improvement from slow reading speed to normal reading performance at Level 2 (Figure 4). The reading speed further improved to $69.62 \mathrm{wpm}$ at week 6 and reached $96.21 \mathrm{wpm}$ at week 12 . For the simple magnifier group, the reading performance only reached the normal range at week 6 , with a speed of $55.86 \mathrm{wpm}$, and a speed of $66.42 \mathrm{wpm}$ at week 12 . On the other hand, the typoscope and control groups did not show any significant improvement in reading performance throughout the 12 -week intervention (Figure 4).

The mean reading speed before the intervention for all four groups is shown in Table 2 . These findings indicate that the children with dyslexia who participated in this study had similar reading performance for both Levels 1 and 2. Reading performance of children with dyslexia at both Level 1 and 2 showed a significant improvement from before to after intervention when simple magnifiers and VTMs were used as reading aids, as shown in Table 2 (all $P<0.05$ ). The reading performance of children with dyslexia (Level 1 and Level 2) using a typoscope remained in the slow category, even after 12 weeks of intervention. However, children in the simple magnifier group, at both Levels 1 and 2 , showed significant differences $(P<0.05)$ in reading speed after the 12 -week intervention. In general, their reading speed showed a 2 -fold increase at both Levels 1 and 2. Moreover, the VTM group showed a 2.5 times faster reading speed post-intervention as compared to pre-intervention, and the reading performance changed from the slow category to the normal reading category. However, for the control group, reading speed did not show any significant improvement $(P>0.05)$ for either level, and remained in a slow category. 


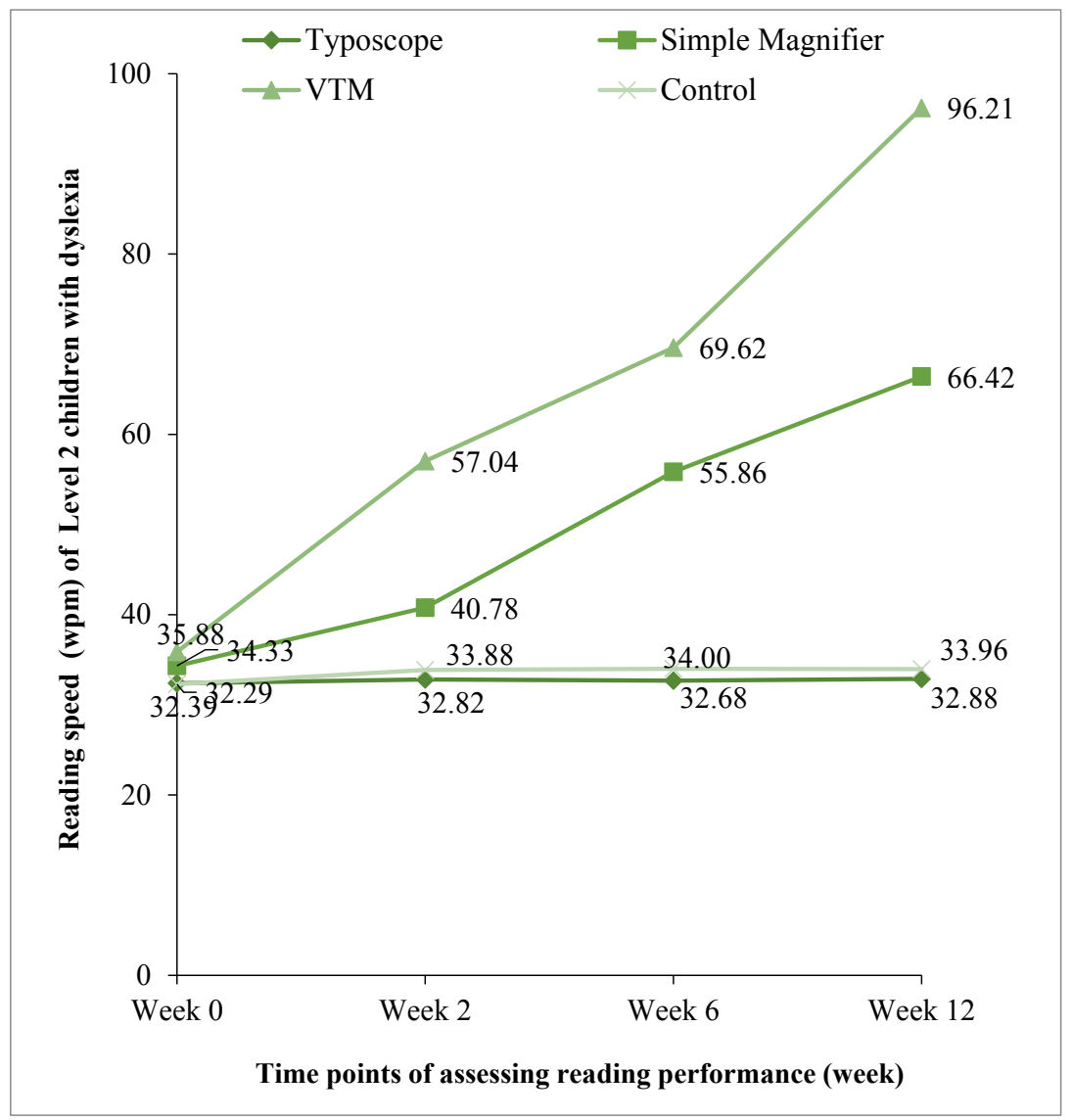

Figure 4. Reading performance of Level 2 children with dyslexia, assessed by reading speed (word per minute [wpm]) using the UKM Malay Language-Related Word Reading Text Test, with different types of visual aids.

Table 2. Comparison of mean reading performances pre- and post-intervention for 80 children with dyslexia using a typoscope, simple magnifier, visual tracking magnifier, and the control intervention

\begin{tabular}{|c|c|c|c|c|}
\hline Children with dyslexia & Types of intervention & Pre, Mean \pm SD $^{*}$ & Post, Mean \pm SD $^{*}$ & $P$-value \\
\hline \multirow{4}{*}{$\begin{array}{l}\text { Level 1, 7- to 9-year-olds } \\
(\mathrm{n}=33)\end{array}$} & Control, $(n=7)$ & $33.06 \pm 1.49$ & $32.70 \pm 2.07$ & 0.23 \\
\hline & Typoscope, $(n=9)$ & $33.57 \pm 2.50$ & $34.29 \pm 1.43$ & 0.06 \\
\hline & Simple Magnifier, $(\mathbf{n}=9)$ & $31.73 \pm 2.56$ & $69.43 \pm 5.28$ & $<0.001$ \\
\hline & VTM, $(\mathbf{n}=\mathbf{8})$ & $37.82 \pm 3.20$ & $94.99 \pm 13.21$ & 0.01 \\
\hline \multirow{4}{*}{$\begin{array}{l}\text { Level 2, 10- to 12-year-olds } \\
(\mathrm{n}=47)\end{array}$} & Control, $(n=13)$ & $32.29 \pm 4.05$ & $33.96 \pm 1.64$ & 0.06 \\
\hline & Typoscope, $(\mathbf{n}=11)$ & $32.39 \pm .83$ & $32.88 \pm 1.97$ & 0.09 \\
\hline & Simple Magnifier, $(n=11)$ & $34.33 \pm 1.94$ & $66.42 \pm 3.85$ & $<0.001$ \\
\hline & VTM, $(n=12)$ & $35.88 \pm 3.12$ & $96.21 \pm 11.1$ & $<0.001$ \\
\hline
\end{tabular}

Abbreviations: SD, standard deviation; n, number; VTM, visual tracking magnification; wpm, words per minute. $P$-values $<0.05$, are shown in bold. Note:"Mean \pm SD of reading performance (reading speed $[\mathrm{wpm}]$ ); pre, pre-intervention at baseline; post, postintervention at week 12 .

\section{DISCUSSION}

This study found that the reading performance of a group of primary school children with dyslexia, using a VTM, increased 2.5 times as compared to the reading speed prior to the 12 -week intervention, for both Level 1 and Level 2. This is because the VTM enlarged the size of the printed text by 1.7 times the original size. This means that, for Level 1, the print size increased from font size 16 to size 27.2, and for Level 2, it increased to size 23.8. This finding was supported by Martelli et al., who demonstrated an improvement in reading rate 
with the increase in letter size for each individual, up to a maximum ( $40 \mathrm{wpm}$ in children with dyslexia versus $110 \mathrm{wpm}$ in controls) [24]. It has been suggested that children with dyslexia also needed a larger print size than normal to facilitate reading and letter recognition processes [25]. Moreover, a study by Spinelli et al. suggested that children with dyslexia need a larger print size because of lateral crowding [26]. Thus, VTM use improved letter recognition by children with dyslexia and reduced errors while reading. A previous study also reported that an increase in character size, line contrast, and in visual span size changed the reading speed in children with dyslexia [27], which supports our findings, where the reading performance of a group of children with dyslexia using VTM and magnifying glass showed faster reading speed than did those who used a typoscope or the control intervention. Furthermore, the results of Cheong et al.s study also supported this study, in finding that subjects were more comfortable reading using a magnifying glass combined with a line indicator [28].

We assessed reading performance in children with dyslexia at weeks $0,2,6$, and 12 . The VTM and simple magnifier groups showed significant improvement in reading performance. The increased reading speed of Level 1 and 2 students with dyslexia was best demonstrated by the VTM group, followed by the simple magnifier, typoscope, and finally the control group. A possible reason for reading better with a VTM is that it is not only enlarged the text, but also had a window to help students with dyslexia trace the lines of text and help the movement of the eyes while reading [29]. The VTM also has two semi-circular amplifiers that reduce the glare effect, and increase the contrast and indicator space. All these factors help to improve reading performance in children with dyslexia in reading speed or higher reading rate than simple magnifiers, typoscopes, or control panels. Although this study showed a significant improvement in reading speed with a simple magnifier, a study by Bowers et al. [30] contradicted the findings, where they found that the use of magnifying glasses caused some problems in lens navigation while reading. They reported that, when reading using a magnifying glass, the reading performance would be slowed because of the navigation factor of the magnifying glass [30]. The possible difference in the outcome of both studies was due to the study participants. Our study involved children with dyslexia, whereas Bowers et al. included visually impaired subjects [30].

This study recruited children with dyslexia and provided training to read with simple visual aids, namely, Typoscope, magnifying glass, and VTM. The reading speed improved significantly after training with simple visual aids. We included subjects with nearly similar reading performance and of all the visual aids, VTM was the most promising device, followed by a simple magnifier. It is advisable to prescribe and train children with dyslexia with proper visual aids to improve reading performance, as also reported by Cox et al., who showed that training children using visual aids is effective at an age as early as $4.67 \pm 0.6$ years [31]. In addition, recent studies also supported that visual attention training improved reading capabilities, and Trigram visuo-perceptive training improved the reading rate in children with dyslexia [32, 33]. In future studies, it will be necessary to consider variable baseline reading performance and the impact of training with visual aids thereon. In addition, this study stopped the intervention at 12 weeks. The observation time should be extended further to observe the sustainability of improved reading performance after discontinuation of the intervention. Moreover, reading comprehension and eye movements during reading with visual aids need to be considered in future studies.

\section{CONCLUSIONS}

Simple visual aids, i.e., a VTM and a simple magnifier, improved reading performance in children with dyslexia. However, training with a typoscope did not significantly improve the reading speed. Because VTM intervention improved reading speed to a normal value, we suggest that this should be used as part of rehabilitation or intervention for all children with dyslexia, particularly those participating in dyslexia programs in schools. However, future studies with longer follow-up periods are needed to confirm the sustainability of this improved reading performance after discontinuation of the intervention.

\section{ETHICAL DECLARATIONS}

Ethical approval: This study followed the Helsinki Declaration for Human Subjects and was approved by the Universiti Kebangsaan Malaysia (UKM) Research and Medical Ethics Research Committee (UKM 1.5.3.5/244/ SPP2/FF1932007). This study was also approved by the Ministry of Education (MOE), and informed consent was obtained from the participants' parents.

Conflict of interests: None 


\section{FUNDING}

The authors acknowledge the financial assistance received from the Ministry of Science and Technology Malaysia (grant code 06-01-02-SF0315).

\section{ACIKNOWLED GEMENT}

The author would like to thank the children with dyslexia who participated in this study, as well as the Ministry of Education Malaysia.

\section{REFERENCES}

1. Al-Shidhani TA, Arora V. Understanding Dyslexia in Children through Human Development Theories. Sultan Qaboos Univ Med J. 2012;12(3):286-94. doi: 10.12816/0003141 pmid: 23269949

2. Lin Y, Zhang X, Huang Q, Lv L, Huang A, Li A, et al. The Prevalence of Dyslexia in Primary School Children and Their Chinese Literacy Assessment in Shantou, China. Int J Environ Res Public Health. 2020;17(19):7140. doi: 10.3390/ijerph17197140 pmid: 33003545

3. Roongpraiwan R, Ruangdaraganon N, Visudhiphan P, Santikul K. Prevalence and clinical characteristics of dyslexia in primary school students. J Med Assoc Thai. 2002;85 Suppl 4:S1097-103. pmid: 12549782

4. Miles TR. Some problems in determining the prevalence of dyslexia. Electronic Journal of Research in Educational Psychology 2004;2:5-12 Link

5. Lyytinen H, Erskine J, Hämäläinen J, Torppa M, Ronimus M. Dyslexia-Early Identification and Prevention: Highlights from the Jyväskylä Longitudinal Study of Dyslexia. Curr Dev Disord Rep. 2015;2(4):330-8. doi: 10.1007/s40474-015-0067-1 pmid: 26543798

6. Cowen C (2016). 'How widespread is dyslexia?' International Dyslexia Association. Available at: https://dyslexiaida.org/howwidespread-is-dyslexia/ (Accessed: June 01, 2021)

7. Ong PH, Ong PT, Ong PL, Konting MM, Zaidi Adruce SA, Pang V. Dyslexia Among Undergraduates in Malaysian Universities: A Mixed-Method Study of Prevalence, Academic Performances, Academic Difficulties and Coping Strategies. International Journal of Diversity in Organisations, Communities \& Nations. 2009;9(2):43-56. doi: 10.18848/1447-9532/CGP/v09i02/39717

8. Wilkins A. Coloured overlays and their effects on reading speed: a review. Ophthalmic Physiol Opt. 2002;22(5):448-54. doi: 10.1046/j.1475-1313.2002.00079.x pmid: 12358317

9. Singleton C, Henderson LM. Computerized screening for visual stress in children with dyslexia. Dyslexia. 2007;13(2):130-51. doi: 10.1002/dys.329 pmid: 17557688

10. Sharanjeet K, Mohamed Z, Jumadi SJ. Status persepsi penglihatan, pergerakan mata dan kelancaran membaca kanak-kanak disleksia [Visual perception status, eye movements and reading fluency of dyslexic children]. Sihat. 2008;148-152. Malay.

11. Stein JF, Richardson AJ, Fowler MS. Monocular occlusion can improve binocular control and reading in dyslexics. Brain. 2000;123 (Pt 1):164-70. doi: 10.1093/brain/123.1.164 pmid: 10611130

12. Evans B (2004). 'The role of optometrist in dyslexia. Part 2: Optometric correlates of dyslexia. Continuing Professional Development. pp: 35-41. Available at: https://www.acotv.org/media/com_lazypdf/pdf/optometry_and_dislexia_2.pdf (Accessed: June 01, 2021)

13. Evans BJW, Stevenson SJ. The Pattern Glare Test: a review and determination of normative values. Ophthalmic Physiol Opt. 2008;28(4):295-309. doi: 10.1111/j.1475-1313.2008.00578.x pmid: 18565084.

14. Perea M, Panadero V, Moret-Tatay C, Gómez P. The effects of inter-letter spacing in visual-word recognition: Evidence with young normal readers and developmental dyslexics. Learn Ins. 2012;22(6):420-30. doi: 10.1016/j.learninstruc.2012.04.001

15. Zorzi M, Barbiero C, Facoetti A, Lonciari I, Carrozzi M, Montico M, et al. Extra-large letter spacing improves reading in dyslexia. Proc Natl Acad Sci U S A. 2012;109(28):11455-9. doi: 10.1073/pnas.1205566109 pmid: 22665803

16. Bucci MP, Carzola B, Fiucci G, Potente C, Caruso L. Computer Based Oculomotor Training Improves Reading Abilities in Dyslexic Children: Results from A Pilot Study. Sports Inj Med 2018 (1):1-6. doi: 10.29011/2576-9596/100030

17. Cancer A, Bonacina S, Antonietti A, Salandi A, Molteni M, Lorusso ML. The Effectiveness of Interventions for Developmental Dyslexia: Rhythmic Reading Training Compared With Hemisphere-Specific Stimulation and Action Video Games. Front Psychol. 2020;11:1158. doi: 10.3389/fpsyg.2020.01158 pmid: 32581961

18. Seki A, Kassai K, Uchiyama H, Koeda T. Reading ability and phonological awareness in Japanese children with dyslexia. Brain Dev. 2008;30(3):179-88. doi: 10.1016/j.braindev.2007.07.006 pmid: 17720344

19. Ministry of Education Malaysia (2010). Bahasa Malaysia: Tahun 1 Sekolah Kebangsaan Buku Teks. Kuala Lumpur: Dewan Bahasa dan Pustaka. Available at: https://www.scribd.com/doc/233441529/Modul-Literasi-Asas-1-Murid-jilid-2 (Accessed: Sep 01, 2021)

20. Ministry of Education Malaysia (2011). Modul Pengajaran Asas Literasi Asas 1: Program Linus. Putrajaya: Ministry of Education Malaysia. Available at: https://www.scribd.com/doc/233441529/Modul-Literasi-Asas-1-Murid-jilid-2 (Accessed: Sep 01, 2021)

21. Kementerian Pelajaran Malaysia (2005). Daftar Kata Bahasa Melayu Sekolah Kebangsaan. Putrajaya: Pusat Perkembangan Kurikulum. Available at: https://www.moe.gov.my/en/muat-turun/pekeliling-dan-garis-panduan/ikhtisas/2005 (Accessed: Sep 01, 2021)

22. Ministry of Education Malaysia (2013). Malaysian Education Blueprint 2013-2025 (Preschool to Post-Secondary Education). Putrajaya: Kementerian Pendidikan Malaysia. Available at: https://www.moe.gov.my/menumedia/media-cetak/penerbitan/ dasar/1207-malaysia-education-blueprint-2013-2025/file (Accessed: Sep 01, 2021)

23. Omar R, Bauri N, Knight VF, Mohamed Z. Pembangunan Ujian Teks Bacaan Perkataan Berkait Bahasa Melayu Universiti Kebangsaan Malaysia [The Development of Universiti Kebangsaan Malaysia Malay Language Related Word Reading Text Test]. Jurnal Sains Kesihatan Malaysia (J Med Health Sci). 2015;13(1):51-56. Malay. Link

24. Martelli M, Di Filippo G, Spinelli D, Zoccolotti P. Crowding, reading, and developmental dyslexia. J Vis. 2009;9(4):14.1-18. doi: 10.1167/9.4.14 pmid: 19757923 
25. O'Brien BA, Mansfield JS, Legge GE. The effect of print size on reading speed in dyslexia. J Res Read. 2005;28(3):332-49. doi: 10.1111/j.1467-9817.2005.00273.x pmid: 16601822

26. Spinelli D, De Luca M, Judica A, Zoccolotti P. Crowding Effects on Word Identification in Developmental Dyslexia. Cortex. 2002;38(2):179-200. doi: 10.1016/s0010-9452(08)70649-x pmid: 12056688

27. Legge GE, Cheung S-H, Yu D, Chung STL, Lee H-W, Owens DP. The case for the visual span as a sensory bottleneck in reading. J Vis. 2007;7(2):9.1-15. doi: 10.1167/7.2.9 pmid: 18217824

28. Cheong AMY, Bowers AR, Lovie-Kitchin JE. Does a Line Guide Improve Reading Performance with Stand Magnifiers? Optom Vis Sci. 2009;86(9):E1078-E85. doi: 10.1097/OPX.0b013e3181b4c4d9 pmid: 19661837

29. Evans BJW, Stevenson SJ. The Pattern Glare Test: a review and determination of normative values. Ophthalmic Physiol Opt. 2008;28(4):295-309. doi: 10.1111/j.1475-1313.2008.00578.x pmid: 18565084

30. Bowers A, Cheong AMY, Lovie-Kitchin JE. Reading With Optical Magnifiers: Page Navigation Strategies and Difficulties. Optom Vis Sci. 2007;84(1):9-20. doi: 10.1097/01.opx.0000254035.39055.05 pmid: 17220774

31. Cox RF, Reimer AM, Verezen CA, Smitsman AW, Vervloed MP, Boonstra NF. Young children's use of a visual aid: an experimental study of the effectiveness of training. Dev Med Child Neurol. 2009;51(6):460-7. doi: 10.1111/j.1469-8749.2008.03228.x pmid: 19170723

32. Caldani S, Gerard C-L, Peyre H, Bucci MP. Visual Attentional Training Improves Reading Capabilities in Children with Dyslexia: An Eye Tracker Study During a Reading Task. Brain Sci. 2020;10(8):558. doi: 10.3390/brainsci10080558 pmid: 32824168

33. Aleci C, Belcastro E, Canavese L. Visual training helps improve reading in dyslexic children with abnormal crowding. Ophthalmology Research: An International Journal, 3(3), 85-94. doi: 10.9734/OR/2015/15409 